\title{
Prevalence of Psychiatric Morbidity and Cognitive Impairment among Patients Attending the Rural Noncommunicable Disease Clinic
}

\author{
Aseem Mehra ${ }^{1}$ Garima Sangwan ${ }^{2}$ Sandeep Grover ${ }^{1}$ \\ ${ }^{1}$ Department of Psychiatry, Postgraduate Institute Medical \\ Education and Research, Chandigarh, Punjab, India \\ ${ }^{2}$ Department of Community Medicine and School of Public \\ Health, Postgraduate Institute Medical Education and Research, \\ Chandigarh, Punjab, India
}

Soundappan Kathirvel ${ }^{2}$ Ajit Avasthi ${ }^{1}$

J Neurosci Rural Pract 2020;11:585-592

\begin{abstract}
Address for correspondence Aseem Mehra, MD, Department of Psychiatry, Postgraduate Institute Medical Education and Research, Chandigarh, Punjab, India (e-mail: aseemmehra86@gmail.com).
\end{abstract}

\begin{abstract}
Objective This study aimed to assess the prevalence of cognitive impairment and psychiatric morbidity among the patients attending the rural noncommunicable disease clinic after controlling for various confounders (i.e., psychological morbidity, obesity, gender, level of education, duration of the illness and age).

Materials and Methods One-hundred twenty-four patients were evaluated on the Hindi Mental State Examination for the cognitive function, Physical Health Questionnaire-9 for depression, and Generalized Anxiety Disorder-7 for anxiety disorders.

Results About one-fourth (26.6\%) of the participants had cognitive impairment. The prevalence of cognitive impairment was more among patients with hypertension (35.5\%) as compared with the diabetes mellitus (13.6\%) and those with comorbid hypertension and diabetes mellitus (26.6\%). About one of the participants had depression (35.5\%) and $29 \%$ of the patients had anxiety disorder. No significant difference was found in the level of cognitive deficits between those with hypertension and diabetes mellitus, when the confounding factors were not taken into account in the analysis. However, after controlling for psychiatric morbidity, obesity, gender, level of

Keywords

- cognitive impairment

- noncommunicable disease

- psychological morbidity

- cognitive neuroscience education, duration of the illness and age, those with hypertension were found to have significantly higher level of cognitive impairment compared with those with diabetes mellitus. A higher level of dysfunction was seen in the domains of orientation, registration, attention, recall, language, and visuospatial domains.

Conclusion Present study suggests that patients of hypertension have higher level of cognitive impairment, when compared with those with diabetes mellitus, even after controlling for various confounders. Lack of difference between the two groups can be accounted by the confounding variables.
\end{abstract}

\section{Introduction}

Among all major health threats to emerge in the 21st century, none has challenged the foundations of public health as profoundly as the rise of chronic noncommunicable diseases (NCDs). The common NCDs include hypertension (HTN), diabetes mellitus (DM), ischemic heart diseases, cancers, osteoporosis, and chronic kidney diseases. The burden of NCDs is rising rapidly and remains among the most common cause of mortality and morbidity in the world. ${ }^{1}$ As per the World Health Organization (WHO), more than 3.6 crore death occurred each year from the NCDs with majority of the death occurring in developing countries such as India and China. ${ }^{2}$ Among the various NCDs, cardiovascular and DM 
are the leading causes of mortality and morbidity across the world. ${ }^{3,4}$ Looking at the current trend, by 2020, 73\% of deaths and $60 \%$ of the disease will be attributable to NCDs globally. ${ }^{5}$ As per WHO, in India in cardiovascular diseases are the most common NCDs which cause deaths (24\%), followed by respiratory diseases (11\%), injuries (10\%), and others(10\%). ${ }^{6}$ Among NCDs, diabetes and HTN have a rising trend. It is projected that size of HTN group is expected to increase by $108 \%$ in India by $2050{ }^{7,8}$ By 2030, the number of people with diabetes will increase from 40.6 million to 79.4 million. $^{8-10}$

Studies from across the world have shown the association between NCDs and the decline of cognitive function leading to mild cognitive impairment (MCI) or dementia. ${ }^{11-14}$ However, the etiological pathway of this relationship is not known. MCI is the transitional phase between the normal aging process and dementia. ${ }^{15,16}$ The cognitive decline can impair the quality of life and also increase the burden on the patient as well as to their caregivers, leading to more financial constraints, stigmatization, increase distress, and isolation from the society. ${ }^{13}$

Studies around the world showed that patients with NCDs reported prevalence of cognitive impairment $(\mathrm{CI})$ to be 1.7 to $40 \% .{ }^{17-19}$ Studies from India too suggest prevalence of CI to be around 4.6 to $10.8 \%$ in NCDs and have found a significant association between the NCDs and CI. ${ }^{11-14,16,20}$ In recent years, there are accumulating epidemiological evidence that HTN and diabetes are important risk factors for MCI and dementia. ${ }^{21-26}$

Research showed that midlife DM had been associated with the occurrence of $\mathrm{CI}^{27-29}$ In terms of specific domains of cognitive functions, DM has been associated with impaired verbal memory, impaired attention, decreased executive function and processing and motor speed. ${ }^{30-32}$ The risk factors for cognitive dysfunction in DM include obesity, female gender, hyperglycemia or poor glycemic control, the extremity of age, longer duration of illness, presence of microvascular complications, presence of comorbid depression, anxiety, and HTN. ${ }^{14,33-38}$

The relationship between HTN and CI has also been documented, but findings are inconsistent, with few studies suggesting that high blood pressure (not necessarily HTN) is associated with $\mathrm{Cl}^{39,40}$ and others suggest an association of $\mathrm{CI}$ with low blood pressure $\mathrm{p}^{41,42}$ and a few suggest a "U"-shaped relationship between blood pressure and cognitive functioning. ${ }^{43}$ However, a few studies reporting no association, ${ }^{44,45}$ majority of the studies support the association of cognitive decline and HTN. ${ }^{46-48}$ Risk factors associated with $\mathrm{CI}$ include female gender, poor medication compliance, poorly controlled blood pressure, elderly age, low level of education, higher number of medication, active treatment, the type of cognitive assessment scale, presence of comorbid depression, and DM. . $^{249,50}$

Patients with NCDs have also been shown to have a high prevalence of mental disorders. In HTN, the prevalence of depression varies from 15 to $58.1 \%^{51,52}$ and that for anxiety disorders varies from 5 to $42.3 \% .^{51,53}$ The rate of depression in patients with DM ranges from 14 to $41 \%{ }^{54,55}$ Those with comorbid DM and HTN, the prevalence rate of depression and anxiety rises up to $60.9 \%{ }^{56}$ The coexistence of the NCDs and mental disorders has an important implication in terms of prognosis, quality of life, cost-effectiveness, general well-being, and expectancy of life. ${ }^{57,58}$ The presence of psychiatric illness among patients with physical illnesses leads to poor treatment adherence, poor lifestyle, increased cost of the treatment, poor quality of life, worsening of physical illness, work absenteeism, increased hospital visits, poor selfcare, and higher mortality. ${ }^{59-61}$

Studies that have assessed CI in NCDs have not controlled for various confounding variables, such as depression, anxiety, obesity, gender, level of education, duration of the illness, and age of the participants, which can also influence cognitive functioning. Accordingly, there is a need to control for these variables to have a better understanding of the prevalence of $\mathrm{CI}$ among patients with NCDs. Thus, the current study aimed to evaluate prevalence of $\mathrm{CI}$ among patients with NCDs attending the NCD clinic at the rural health clinic (RHC) in Naraingarh, North India, after controlling for depression, age, obesity, gender, level of education, duration of the illness, and anxiety.

\section{Materials and Methods}

It was a cross-sectional study conducted among the patients attending the NCDs clinic of a community RHC run in collaboration with the Postgraduate Institute Medical Education and Research (PGIMER), Chandigarh. This clinic was established exclusively for patients suffering from diabetes mellitus, HTN, hypothyroidism, and rheumatoid arthritis. The clinic runs every Tuesday and Thursday in a rural community health center, Nariangarh. On average, 40 to 50 patients attend the clinic each day and avail the health services. The medications are available free of cost at the rural community health center. At a stretch, medications are dispensed for a maximum of 2 weeks.

A faculty member from the Department of School of Public Health, PGIMER, Chandigarh, is the in-charge of the clinic, and the services are mainly provided by a senior resident and junior residents from the Department of School of Public Health, under the supervision of the faculty member. Other staff of the NCD clinic includes the nursing staff, public health nurse, and health worker.

The study period was from June to July 2018. At the time of the beginning of the study, 208 patients were registered with the NCD clinic. A majority of patients were suffering from HTN, diabetes, or both; only a few patients diagnosed with rheumatoid arthritis or hypothyroidism.

The approval was obtained from Ethics Committee of the Institute. To be included in the study, the study participants should be $\geq 18$ years old of either gender and cooperative for physical and mental status examination, who provided the written informed consent. Patients who refused to give consent and were severely ill, had a history of mental illness, were on psychotropics, or had severe visual and auditory impairment to interfere in the formal assessment were excluded.

All adult patients attending NCD clinic were approached, explained about the study, and those fulfilling the selection 
criteria were recruited into the study. Senior resident doctors, involved in the NCD clinic, recruited the patients and administered instruments for assessment of cognitive functions, depression, and anxiety.

Those patients who screened positive for psychiatric illness (depression, anxiety, or $\mathrm{CI}$ ) were referred to a psychiatric out-reach outpatient clinic for further evaluation. The psychiatric out-reach outpatient's clinic runs every Wednesday by the Department of Psychiatry, PGIMER, Chandigarh, in collaboration with the Department of School of Public Health and Community Health Center of Naraingarh.

\section{Instruments}

Hindi Mental Status Examination (HMSE): Cognitive functions were assessed by using HMSE. This is designed mainly for illiterate Hindi speaking population. It can be said that this a modified version of mini-mental state examination (MMSE) with a less emphasis on calculation ability. ${ }^{62}$ It is a validated tool to evaluate cognitive decline. The sensitivity and specificity of the scale are 94 and $98 \%$, respectively. ${ }^{63,64}$ Many researchers have used it for screening not only for dementia but also for delirium, but the authors did not present the detailed scores. Hence, the HMSE suitably adapted for the participants. In the current study, those with HMSE scores $\leq 25$ were considered "cognitively impaired" 64 .

Patient Health Questionnaire-9 (PHQ-9): Hindi version of this tool was used to assess depression. It is a self-report questionnaire, which comprises of nine items, each evaluating the Diagnostic and Statistical Manual (DSM) of Mental Disorders criteria of depression, rated as "0" (not at all) to "3" (nearly every day). Score $\geq 10$ has a sensitivity of $88 \%$ and a specificity of $88 \%$ for the diagnosis of major depression made by a mental health profession. We used the cutoff of 10 for making the diagnosis of depression. ${ }^{65}$

Generalized Anxiety Disorder-7 (GAD-7) scale: It is a 7-item scale with good reliability as well as a criterion, constructs, procedural, and factorial validity. Mild, moderate, and severe levels of anxiety are interpreted on the cutoff points of 5,10 , and 15 . There is a good agreement between self-report and interviewer-administered versions of the scale. However, the diagnostic threshold has been reported to be a cutoff score of 10 or more. In the present study, a cutoff score of 10 or more was used to make the diagnosis of an anxiety disorder, which has been used in the previous studies. ${ }^{66,67}$

Sociodemographic profiles such as age, gender, type of family, socioeconomic status, occupation, marital status, number of years of education, and locality were recorded.

Details of the NCD, such as type of NCDs (HTN, DM, or both), duration of illness, age of onset, blood pressure, height in centimeters, weight in kilograms, were recorded. The height was measured by making the patient stand with their back against a fixed wall by using a stadiometer. The weight was measured by using a particular standard weighing machine. The blood pressure was recorded by using a mercury sphygmomanometer; the standard location of the measurement was the brachial artery.

\section{Statistical Analysis}

The statistical analysis was performed using SPSS 14.0 for Windows (SPSS for Windows, Version 14.0. Chicago, SPSS Inc., Chicago, Illinois, United States). Descriptive analysis was performed using mean and standard deviation (SD) with a range for continuous variables. Descriptive analysis was computed as frequency and percentages for discontinuous variables. For the inferential analysis, correlation analysis was done. Analysis of covariance was applied to see the relationship between the domain of the HMSE and NCDs. The dependent variables were DM, HTN, and comorbid HTN and DM. The independent variables were the mean score of the HMSE and various domains of the HMSE. The covariates were age, gender, duration of the illness, age of onset, depression, anxiety, body mass index (BMI), and education.

\section{Results}

One-hundred twenty-four participants were recruited into the present study. Mean age of the participants was 55.5 years (range: 26-90, SD: 11.9). The mean number of years of education was 5.7 (SD: 5.2). A majority of the participants were from a rural background and were not on any paid employment. About two-thirds were females. A little more than onethird ( $n=48,38.7 \%)$ patients were diagnosed with HTN only, one-sixth $(N=22 ; 17.7 \%)$ were diagnosed with DM only, and 54 (43.5\%) patients were diagnosed with both HTN and DM. The mean BMI of the participants was $27.3 \mathrm{~kg} / \mathrm{m}^{2}$ (-Table $\mathbf{1}$ ).

In terms of cognitive functions, the mean total score of the study sample was 26 (SD: 4.1), and 33 (26.6\%) patients had HMSE score $\leq 24$, indicating possible $\mathrm{CI}$. A slightly more than one-third of the study participants were diagnosed with depressive disorder ( $n=44,35.5 \%)$ and $29 \%(n=36)$ of the participants were diagnosed with an anxiety disorder. Onefourth of patients had both depressive and anxiety disorders. In general, $\mathrm{CI}$ was higher among patients with psychiatric morbidity (-Table 2).

\section{Relationship of Cognitive Functions with NCDs}

To assess the impact of NCDs on cognitive functions, the study sample was divided into three groups: DM (Group-I), HTN (Group-II), and those with both (Group-III). When the three groups were compared, no significant differences were seen. However, when age, gender, duration of illness, number of year of education, mean score of PHQ-9, mean score of GAD7 , and mean BMI were taken as covariates as is evident from - Table 3, patients with HTN performed poorly than those with DM on all the domains of HMSE and had significantly lower HMSE score. When the combined DM and HTN group was compared with those with only DM, combined group had significantly scored low on HMSE, performed poorly on attention, language and visuospatial abilities. On the similar lines, when the combined group was compared with those with HTN only, significant differences were noted for total HMSE score and all the domains of HMSE except for recall, 
Table 1 Sociodemographic and clinic profile

\begin{tabular}{|l|l|}
\hline Variables & $\begin{array}{l}\text { Mean/frequency } \\
(\boldsymbol{n}=124)\end{array}$ \\
\hline Age (in years) & $55.1(11.9)$ \\
\hline Sex-female & $83(66.9 \%)$ \\
\hline Marital-married & $100(80.6 \%)$ \\
\hline Education (number of years) & $5.7(5.2)$ \\
\hline Duration of illness (in months) & $\begin{array}{l}63.4(65.1) \text { (range: } \\
1-364)\end{array}$ \\
\hline $\begin{array}{l}\text { Occupation-not on paid } \\
\text { employment }\end{array}$ & $90(72.6 \%)$ \\
\hline Income (patient) & $4,394.0(9,639.8)$ \\
\hline $\begin{array}{l}\text { Socioeconomic status-lower/ } \\
\text { middle/upper }\end{array}$ & $\begin{array}{l}65(52.4 \%) / 55(44.4 \%) / \\
(3.2 \%)\end{array}$ \\
\hline Type of family-extended/joint & $68(54.8 \%)$ \\
\hline Locality-rural & $120(96.8 \%)$ \\
\hline Primary diagnosis & $48(38.7 \%)$ \\
\hline Hypertension & $22(17.7 \%)$ \\
\hline Diabetes Mellitus & $54(43.5 \%)$ \\
\hline $\begin{array}{l}\text { Hypertension+ diabetes } \\
\text { mellitus }\end{array}$ & $63.4(65.1)$ \\
\hline $\begin{array}{l}\text { Mean duration of illness } \\
\text { (in months) }\end{array}$ & \begin{tabular}{l}
$134.5(16.2)$ \\
\hline Systolic blood pressure in mm Hg
\end{tabular} \\
\hline Diastolic blood pressure in mm Hg & $81.10 .1)$ \\
\hline Body mass in Index in kg/m² & \\
\hline
\end{tabular}

with patients with HTN only performing poorly than those with both HTN and DM.

\section{Discussion}

In developing countries such as India, the prevalence of NCDs and the elderly population is increasing rapidly. Despite these facts, so far, $\mathrm{CI}$ in patients with NCDs largely remains neglected. The present study shows prevalence of $\mathrm{CI}$ in patients with NCDs was $26.6 \%$, the prevalence of depression was $35.5 \%$, and that of anxiety disorder was $29 \%$. Onefourth of patients had both depressive and anxiety disorders. Previous studies from India, which have evaluated prevalence of $\mathrm{CI}$ in elderly (aged $>65$ years) by using the HMSE or modified MMSE, report prevalence to vary from 3.5 to $11.5 \% .^{63,68-72}$ However, none of these studies have been done specifically among the subjects with NCDs. Findings of the current study are compared with these studies, and it is evident that prevalence of $\mathrm{CI}$ is more in patients with NCD. Existing data from other parts of the world suggest that the prevalence of dementia in patients with NCD ranges from 2.34 to 38.6\%73-78 and the current study also reported within range. Among patients with DM, the prevalence of $\mathrm{CI}$ in the present study was $13.63 \%$. Previous studies from India, which have assessed $\mathrm{CI}$ in DM, have reported prevalence rates of $11.6,{ }^{13}$ 13.7 to $16.9,{ }^{9}$ and $33.7 \%,{ }^{12}$ respectively; present study also reported within the range. Similarly, prevalence of $\mathrm{Cl}$ among patients with HTN in the present study was $31.2 \%$. Previous studies from India, which were conducted among patients with HTN, have reported prevalence rates of reported $11.9^{13}$ and $13 \%,{ }^{79}$ respectively. Findings of the present concur with the available literature. Prevalence of $\mathrm{CI}$ among those with both DM and HTN was $26.6 \%$, and this is also supported by the existing literature, which suggests higher prevalence rates when patients have both illnesses. ${ }^{49,80,81}$ These findings suggest that patients with NCDs form a high-risk group for $\mathrm{CI}$ and dementia. Accordingly, there is a need to screen these patients routinely for cognitive functioning, and these patients must be provided information about the development of $\mathrm{CI}$, factors contributing to the same, lifestyle changes, and cognitive exercises to prevent $\mathrm{CI}$ and early detection.

In the present study, psychiatric morbidity was found in $39.51 \%$ of the patients, with depression in $35.5 \%$ and anxiety disorder in $29.9 \%$ of cases, with a majority of them having comorbid depression and anxiety. These prevalence figures are in the reported range in the available literature for psychiatric morbidity among patients with NCD, DM, and HTN from India and abroad. ${ }^{82}$

The present study also supports the existing literature that prevalence of $\mathrm{Cl}$ is higher in the presence of psychiatric morbidity in the form of depression and anxiety disorders..$^{14,38}$

Very few studies have compared the Cls among patients with DM, HTN, and both, after controlling for various confounding variables. In the present study, after controlling for the covariates (age, gender, duration of illness, number of year of education, mean score of PHQ-9, mean score of GAD-7, and BMI) when patients of HTN and DM were compared, patients with HTN were found to have significantly higher level of CI. Further, the higher level of dysfunction was seen in the domains of orientation, registration, attention, recall, language, and visuospatial domains. These findings suggest that HTN possibly has a more negative impact on cognitive functions when compared with DM.

When patients with DM were compared with those with both DM and HTN, those with both the illnesses had higher impairment in the form of lower HMSE score, impairment in attention, language, and visuospatial domains. Similarly, when HTN group was compared with those with both HTN and DM, those with both the illnesses had higher impairment in the form of lower HMSE scores and lower scores in all the domains, except recall. These findings provide preliminary evidence about the differential effect of DM and HTN on cognitive functions.

A small sample size limits the present study. Only HMSE was used to screen for a cognitive profile, which has its limitations. Psychiatric morbidity was evaluated by using PHQ-9 and GAD-7, and the mental health professionals did not confirm the diagnosis. The assessment was cross-sectional. The study did not asses the cognitive profile before the illness, and hence, it cannot be said that the level of cognitive deficits noted can be attributed to the NCDs only. The study did not evaluate the course of the NCDs and fluctuation in the symptoms. Similarly, other factors, such as dietary patterns and lifestyle, were not assessed. The study did not have a comparative group without NCDs.

To conclude, the present study suggests that about one-fourth of patients with NCD have CI and 39.51\% have 
Table 2 Cognitive profile, depressive, and anxiety symptoms as per HMSE

\begin{tabular}{|c|c|}
\hline Variables & Score (mean)[range] \\
\hline Orientation & $9.4(1.1)[5-10]$ \\
\hline Registration & $2.8(0.4)[1-3]$ \\
\hline Attention & $4.3(1.1)[1-5]$ \\
\hline Recall & $2.2(0.7)[0-3]$ \\
\hline Language & $7.4(1.6)[3-9]$ \\
\hline Visuospatial & $1.6(1.2)[0-3]$ \\
\hline Total & $26.0(4.1)[12-30]$ \\
\hline \multicolumn{2}{|l|}{ Severity } \\
\hline Normal ( $\geq 25)$ & $91(73.4 \%)$ \\
\hline Cognitively impaired $(\leq 24)$ & $33(26.6 \%)$ \\
\hline \multicolumn{2}{|l|}{ HMSE score $(\leq 24)$} \\
\hline Among patients with hypertension & $15(31.25 \%)$ \\
\hline Among patients with diabetes mellitus & $3(13.63 \%)$ \\
\hline Among patients with both hypertension and diabetes mellitus & $15(27.77 \%)$ \\
\hline Among patients of hypertension without psychiatric morbidity & $9(28.12 \%)$ \\
\hline Among patients of hypertension with psychiatric morbidity & $6(37.5 \%)$ \\
\hline Among patients of diabetes mellitus without psychiatric morbidity & $1(7.7 \%)$ \\
\hline Among patients of diabetes mellitus with psychiatric morbidity & $2(22.22 \%)$ \\
\hline Among patients with both hypertension and diabetes mellitus and without psychiatric morbidity & $8(26.6 \%)$ \\
\hline Among patients with both hypertension and diabetes mellitus and with psychiatric morbidity & $7(29.16 \%)$ \\
\hline \multicolumn{2}{|l|}{ PHQ severity } \\
\hline Normal or no depression $(<10)$ & $80(64.5 \%)$ \\
\hline Depression $(\geq 10)$ & $44(35.5 \%)$ \\
\hline PHQ total score & $8.3(6.9)$ \\
\hline \multicolumn{2}{|l|}{ Prevalence of depression according to NCDs } \\
\hline Hypertension $(n=48)$ & $14(29.2 \%)$ \\
\hline Diabetes $(n=22)$ & $9(40.9 \%)$ \\
\hline Co-morbid hypertension + diabetes mellitus $(n=54)$ & $21(38.9 \%)$ \\
\hline Psychiatric morbidity in patients with hypertension & $16(33.33 \%)$ \\
\hline Psychiatric morbidity in patients with diabetes mellitus & $9(40.9 \%)$ \\
\hline Psychiatric morbidity in patients with hypertension and diabetes mellitus & $24(44.44 \%)$ \\
\hline Number of patients with psychiatric morbidity & $49(39.51 \%)$ \\
\hline \multicolumn{2}{|l|}{ GAD severity } \\
\hline Normal or no anxiety disorder & $88(70.96 \%)$ \\
\hline Anxiety disorder & $36(29.0 \%)$ \\
\hline Total score & $7.0(6.2)$ \\
\hline \multicolumn{2}{|l|}{ Prevalence of anxiety according to NCDs } \\
\hline Hypertension & $14(29.2 \%)$ \\
\hline Diabetes mellitus & $6(27.3 \%)$ \\
\hline Comorbid hypertension+diabetes mellitus & $16(29.7 \%)$ \\
\hline Comorbid (anxiety+ depressive) disorder & 31 (25.0\%) \\
\hline
\end{tabular}

Abbreviations: GAD, generalized anxiety disorder; HMSE, Hindi Mental State Examination; NCD, noncommunicable diseases; PHQ, patient health questionnaire. 
Table 3 Correlation of cognitive profile with the NCDs

\begin{tabular}{|c|c|c|c|c|c|c|c|c|c|}
\hline Variables & $\begin{array}{l}\text { Whole } \\
\text { group } \\
(n=124)\end{array}$ & $\begin{array}{l}\text { Hypertension } \\
\text { Group I } \\
(n=48)\end{array}$ & $\begin{array}{l}\text { Diabetes } \\
\text { Group II } \\
(n=22)\end{array}$ & $\begin{array}{l}\text { Diabetes + } \\
\text { hypertension } \\
\text { Group III } \\
(n=54)\end{array}$ & F-Value & $p$-Value & $\begin{array}{l}\text { Comparison } \\
\text { of Group I } \\
\text { vs. II } \\
\text { ANCOVA } \\
\text { F-value } \\
\text { ( } p \text {-value) }\end{array}$ & $\begin{array}{l}\text { Comparison } \\
\text { of Group } \\
\text { II vs. III } \\
\text { ANCOVA } \\
\text { F-value } \\
\text { ( } p \text {-value) }\end{array}$ & $\begin{array}{l}\text { Comparison } \\
\text { of Group I vs. } \\
\text { III ANCOVA } \\
\text { F-value } \\
\text { (p-value) }\end{array}$ \\
\hline $\begin{array}{l}\text { Total HMSE } \\
\text { score }\end{array}$ & $26.0(4.1)$ & $25.3(4.3)$ & $27.8(2.5)$ & $25.9(4.3)$ & 2.894 & $\|>|||>|$ & $\begin{array}{l}5.901 \\
(<0.001)^{\mathrm{a}}\end{array}$ & $\begin{array}{l}2.786 \\
\left(0.010^{\mathrm{b}}\right)\end{array}$ & $\begin{array}{l}4.595 \\
(<0.001)^{\text {a }}\end{array}$ \\
\hline Orientation & $9.4(1.1)$ & $9.2(1.2)$ & $9.8(0.5)$ & $9.3(1.3)$ & 2.567 & $\|>|\|>|$ & $\begin{array}{l}3.659 \\
(0.002)^{c}\end{array}$ & $\begin{array}{l}1.886 \\
(0.077)\end{array}$ & $\begin{array}{l}2.995 \\
(0.005)^{c}\end{array}$ \\
\hline Registration & $2.8(0.4)$ & $2.7(0.4)$ & $2.8(0.4)$ & $2.8(0.4)$ & 0.806 & $\||=|||>\mid$ & $\begin{array}{l}2.906 \\
(0.008)^{c}\end{array}$ & $\begin{array}{l}1.300 \\
(0.259)\end{array}$ & $\begin{array}{l}2.803 \\
(0.008)^{c}\end{array}$ \\
\hline Attention & $4.3(1.1)$ & $4.2(1.1)$ & $4.7(0.8)$ & $4.3(1.2)$ & 2.016 & $\|>\mid\|>1$ & $\begin{array}{l}3.417 \\
(0.003)^{c}\end{array}$ & $\begin{array}{l}2.646 \\
\left(0.014^{b}\right)\end{array}$ & $\begin{array}{l}2.967 \\
(0.005)^{c}\end{array}$ \\
\hline Recall & $2.2(0.7)$ & $2.0(0.7)$ & $2.5(0.5)$ & $2.1(0.7)$ & 5.055 & $\begin{array}{l}\|>\left.\right|^{\mathrm{c}} \\
\|>\|^{b} \\
\|>\mid\end{array}$ & $\begin{array}{l}2.779 \\
(0.011)^{\mathrm{b}}\end{array}$ & $\begin{array}{l}1.513 \\
(0.169)\end{array}$ & $\begin{array}{l}1.842 \\
(0.079)\end{array}$ \\
\hline Language & $7.4(1.6)$ & $7.2(1.7)$ & $7.9(1.2)$ & $7.3(1.6)$ & 1.431 & $\|>\|||>\mid$ & $\begin{array}{l}5.987 \\
(<0.001)^{\mathrm{a}}\end{array}$ & $\begin{array}{l}4.109 \\
(<0.001)^{\mathrm{a}}\end{array}$ & $\begin{array}{l}5.371 \\
(<0.001)^{\mathrm{a}}\end{array}$ \\
\hline Visuospatial & $1.6(1.2)$ & $1.5(1.3)$ & $2.0(1.0)$ & $1.6(1.2)$ & 1.229 & $\|>|\|>|$ & $\begin{array}{l}6.483 \\
(0.001)^{\mathrm{a}}\end{array}$ & $\begin{array}{l}3.651 \\
(0.001)^{c}\end{array}$ & $\begin{array}{l}5.029 \\
(<0.001)^{\mathrm{a}}\end{array}$ \\
\hline
\end{tabular}

Abbreviations: ANCOVA, analysis of covariance; BMI, body mass index; GAD, generalized anxiety disorder; HMSE, Hindi Mental State Examination; $\mathrm{NCD}$, noncommunicable diseases; PHQ, patient health questionnaire.

${ }^{\mathrm{a}} \mathrm{p}<0.001$

${ }^{\mathrm{b}} p<0.05$

${ }^{c} p<0.01$

Note: covariates = age, gender, education, duration of illness, BMI, PHQ total, GAD total.

psychiatric morbidity. The present study also suggests that prevalence of $\mathrm{CI}$ is higher among patients of NCD with psychiatric morbidity. When severity and prevalence of $\mathrm{CI}$ are compared between patients of HTN and diabetic, it was seen that prevalence and severity of cognitive deficits are higher among patients with HTN. Hence, it can be said that patients with NCDs should be routinely screened for cognitive functioning and these patients must be provided information about the development of $\mathrm{CI}$, factors contributing to the same, lifestyle changes and cognitive exercises to prevent $\mathrm{CI}$ and early detection. Similarly, these patients must also be routinely screened for psychiatric morbidity and this must be treated adequately.

\section{Conflict of Interest}

None declared.

\section{References}

1 World Health Organization, Global Report on Diabetes. Geneva: World Health Organization; 2016

2 Nag T, Ghosh A. Cardiovascular disease risk factors in Asian Indian population: a systematic review. J Cardiovasc Dis Res 2013;4(4):222-228

3 World Health Organisation. World Health Day; 2017. Available at: http://www.who.int/campaigns/world-health-day/2017/ en. Accessed June 29, 2020

4 The top 10 causes of death. Mediacenter, Factsheets: World Health Organization (WHO); 2016. Available at: https:// www.who.int/news-room/fact-sheets/detail/the-top10-causes-of-death
5 Wong JS, Karamalakis D. Evaluation of automated hepatitis $C$ core antigen assay in occupational exposure. Pathology 2013;45(5):529-531

6 World Health Organization. World report on disability. 2011

7 Anchala R, Kannuri NK, Pant H, et al. Hypertension in India: a systematic review and meta-analysis of prevalence, awareness, and control of hypertension. J Hypertens 2014;32(6):1170-1177

8 Kearney PM, Whelton M, Reynolds K, Muntner P, Whelton PK, He J. Global burden of hypertension: analysis of worldwide data. Lancet 2005;365(9455):217-223

9 Tiwari SC, Tripathi RK, Farooqi SA, Kumar R, Srivastava G, Kumar A. Diabetes mellitus: a risk factor for cognitive impairment amongst urban older adults. Ind Psychiatry J 2012;21(1):44-48

10 Ramachandran A, Snehalatha C, Kapur A, et al; Diabetes Epidemiology Study Group in India (DESI). High prevalence of diabetes and impaired glucose tolerance in India: National Urban Diabetes Survey. Diabetologia 2001;44(9):1094-1101

11 Kataria L, Pandya H, Shah S, Shah H, Gerg R. Prevalence and pattern of cognitive dysfunction in type 2 diabetes mellitus. Int J Med Appl Sci 2013;2:246-252

12 Khullar S, Kaur G, Dhillon H, et al. The prevalence and predictors of cognitive impairment in type 2 diabetic population of Punjab, India. J Soc Health Diabetes 2017;5:47-53

13 Krishnamoorthy Y, Sarveswaran G, Sakthivel M, Rehman T, Majella MG, Kumar SG. Screening for mild cognitive impairment among noncommunicable disease patients attending a rural primary health center in Puducherry, South India. J Nat Sci Biol Med 2019;10:77-81

14 Zilliox LA, Chadrasekaran K, Kwan JY, Russell JW. Diabetes and cognitive impairment. Curr Diab Rep 2016;16(9):87

15 Das SK, Bose P, Biswas A, et al. An epidemiologic study of mild cognitive impairment in Kolkata, India. Neurology 2007;68(23):2019-2026 
16 Sosa AL, Albanese E, Stephan BC, et al. Prevalence, distribution, and impact of mild cognitive impairment in Latin America, China, and India: a 10/66 population-based study. PLoS Med 2012;9(2):e1001170

17 Lazo-Porras M, Ortiz-Soriano V, Moscoso-Porras M, Runzer-Colmenares FM, Málaga G, Jaime Miranda J. Cognitive impairment and hypertension in older adults living in extreme poverty: a cross-sectional study in Peru. BMC Geriatr 2017;17(1):250

18 Eze C, Basil E, Uma A, Ikenna O.. The prevalence of cognitive impairment amongst type 2 diabetes mellitus patients at Abakaliki South-East Nigeria. J Metab Syndr 2015;4-171

19 Gorska-Ciebiada M, Saryusz-Wolska M, Ciebiada M, Loba J. Mild cognitive impairment and depressive symptoms in elderly patients with diabetes: prevalence, risk factors, and comorbidity. J Diabetes Res 2014;2014:179648

20 Gondim AS, Coelho Filho JM, Cavalcanti AA, et al. Prevalence of functional cognitive impairment and associated factors in Brazilian community-dwelling older adults. Dement Neuropsychol 2017;11(1):32-39

21 Gorelick PB, Scuteri A, Black SE, et al; American Heart Association Stroke Council, Council on Epidemiology and Prevention, Council on Cardiovascular Nursing, Council on Cardiovascular Radiology and Intervention, and Council on Cardiovascular Surgery and Anesthesia. Vascular contributions to cognitive impairment and dementia: a statement for healthcare professionals from the American Heart Association/ American Stroke Association. Stroke 2011;42(9):2672-2713

22 Biessels GJ, Staekenborg S, Brunner E, Brayne C, Scheltens P. Risk of dementia in diabetes mellitus: a systematic review. Lancet Neurol 2006;5(1):64-74

23 Okusaga O, Stewart MC, Butcher I, Deary I, Fowkes FG, Price JF. Smoking, hypercholesterolaemia and hypertension as risk factors for cognitive impairment in older adults. Age Ageing 2013;42(3):306-311

24 Spinelli C, De Caro MF, Schirosi G, et al. Impaired cognitive executive dysfunction in adult treated hypertensives with a confirmed diagnosis of poorly controlled blood pressure. Int J Med Sci 2014;11(8):771-778

25 Uiterwijk R, Huijts M, Staals J, et al. Subjective cognitive failures in patients with hypertension are related to cognitive performance and cerebral microbleeds. Hypertension 2014;64(3):653-657

26 Yamaguchi Y, Wada M, Sato H, et al. Impact of nocturnal heart rate variability on cerebral small-vessel disease progression: a longitudinal study in community-dwelling elderly Japanese. Hypertens Res 2015;38(8):564-569

27 Cukierman T, Gerstein HC, Williamson JD. Cognitive decline and dementia in diabetes-systematic overview of prospective observational studies. Diabetologia 2005;48(12):2460-2469

28 Rawlings AM, Sharrett AR, Schneider ALC, et al. Diabetes in midlife and cognitive change over 20 years: a cohort study. Ann Intern Med 2014;161(11):785-793

29 Chatterjee S, Peters SA, Woodward M, et al. Type 2 diabetes as a risk factor for dementia in women compared with men: a pooled analysis of 2.3 million people comprising more than 100,000 cases of dementia. Diabetes Care 2016;39(2):300-307

30 Monette MC, Baird A, Jackson DL. A meta-analysis of cognitive functioning in nondemented adults with type 2 diabetes mellitus. Can J Diabetes 2014;38(6):401-408

31 Palta P, Schneider AL, Biessels GJ, Touradji P, Hill-Briggs F. Magnitude of cognitive dysfunction in adults with type 2 diabetes: a meta-analysis of six cognitive domains and the most frequently reported neuropsychological tests within domains. J Int Neuropsychol Soc 2014;20(3):278-291

32 Wong RH, Scholey A, Howe PR. Assessing premorbid cognitive ability in adults with type 2 diabetes mellitus-a review with implications for future intervention studies. Curr Diab Rep 2014;14(11):547

33 Akter K, Lanza EA, Martin SA, Myronyuk N, Rua M, Raffa RB. Diabetes mellitus and Alzheimer's disease: shared pathology and treatment? Br J Clin Pharmacol 2011;71(3):365-376

34 de la Monte SM. Brain insulin resistance and deficiency as therapeutic targets in Alzheimer's disease. Curr Alzheimer Res 2012;9(1):35-66

35 Ding J, Strachan MWJ, Reynolds RM, et al; Edinburgh Type 2 Diabetes Study Investigators. Diabetic retinopathy and cognitive decline in older people with type 2 diabetes: the Edinburgh Type 2 Diabetes Study. Diabetes 2010;59(11):2883-2889

36 Ebady SA, Arami MA, Shafigh MH. Investigation on the relationship between diabetes mellitus type 2 and cognitive impairment. Diabetes Res Clin Pract 2008;82(3):305-309

37 Hassing LB, Grant MD, Hofer SM, et al. Type 2 diabetes mellitus contributes to cognitive decline in old age: a longitudinal population-based study. J Int Neuropsychol Soc 2004;10(4):599-607

38 Moheet A, Mangia S, Seaquist ER. Impact of diabetes on cognitive function and brain structure. Ann N Y Acad Sci 2015;1353:60-71

39 Shang S, Li P, Deng M, Jiang Y, Chen C, Qu Q. The age-dependent relationship between blood pressure and cognitive impairment: a cross-sectional study in a rural area of Xi'an, China. PLoS One 2016;11(7):e0159485

40 O'Callaghan S, Kenny RA. Neurocardiovascular instability and cognition. Yale J Biol Med 2016;89(1):59-71

41 Guo Z, Fratiglioni L, Winblad B, Viitanen M. Blood pressure and performance on the Mini-Mental State Examination in the very old. Cross-sectional and longitudinal data from the Kungsholmen Project. Am J Epidemiol 1997;145(12):1106-1113

42 Morris MC, Scherr PA, Hebert LE, et al. Association between blood pressure and cognitive function in a biracial community population of older persons. Neuroepidemiology 2002;21(3):123-130

43 Waldstein SR, Giggey PP, Thayer JF, Zonderman AB. Nonlinear relations of blood pressure to cognitive function: the Baltimore Longitudinal Study of Aging. Hypertension 2005;45(3):374-379

44 Gillett SR, Thacker EL, Letter AJ, et al. Correlates of incident cognitive impairment in the REasons for Geographic and Racial Differences in Stroke (REGARDS) Study. Clin Neuropsychol 2015;29(4):466-486

45 Wadley VG, McClure LA, Howard VJ, et al. Cognitive status, stroke symptom reports, and modifiable risk factors among individuals with no diagnosis of stroke or transient ischemic attack in the REasons for Geographic and Racial Differences in Stroke (REGARDS) Study. Stroke 2007;38(4):1143-1147

46 Muela HCS, Costa-Hong VA, Yassuda MS, et al. Hypertension severity is associated with impaired cognitive performance. J Am Heart Assoc 2017;6(1):e004579

47 Gottesman RF, Schneider AL, Albert M, et al. Midlife hypertension and 20-year cognitive change: the atherosclerosis risk in communities neurocognitive study. JAMA Neurol 2014;71(10):1218-1227

48 Knopman DS, Mosley TH, Catellier DJ, Coker LH; Atherosclerosis Risk in Communities Study Brain MRI Study. Fourteen-year longitudinal study of vascular risk factors, APOE genotype, and cognition: the ARIC MRI Study. Alzheimers Dement 2009;5(3):207-214

49 Hassing LB, Hofer SM, Nilsson SE, et al. Comorbid type 2 diabetes mellitus and hypertension exacerbates cognitive decline: evidence from a longitudinal study. Age Ageing 2004;33(4):355-361

50 Vinyoles E, De la Figuera M, Gonzalez-Segura D. Cognitive function and blood pressure control in hypertensive patients 
over 60 years of age: COGNIPRES study. Curr Med Res Opin 2008;24(12):3331-3339

51 Hamrah MS, Hamrah MH, Ishii H, et al. Anxiety and depression among hypertensive outpatients in Afghanistan: a cross-sectional study in Andkhoy City. Int J Hypertens 2018;2018:8560835

52 Kulkarni VG, Lingappa SH. Prevalence of depression in patients attending general medicine outpatient department for hypertension. Int J Med Sci Public Health 2019;8(2):105-109

53 Saeed KMI. Prevalence of risk factors for non-communicable diseases in the adult population of urban areas in Kabul City, Afghanistan. Cent Asian J Glob Health 2014;2(2):69

54 Rezia R, Islam A, Shariful Islam SM. Depressive symptoms among participants with type 2 diabetes in Southeast Asia: a systematic review. J Diabetol 2018;9:19-24

55 Mukeshimana M, Chironda G. Depression and associated factors among the patients with type 2 diabetes in Rwanda. Ethiop J Health Sci 2019;29(6):709-718

56 Neha T, Mrinmoy A, Susmita C. Suresh Kumar K. Prevalence of common mental disorders among patients with diabetes mellitus and hypertension in an urban east Delhi slum - a cross sectional study. TJP 2015;1(1):27-31

57 Guruprasad KG, Niranjan MR, Ashwin S. A study of association of depressive symptoms among the type 2 diabetic outpatients presenting to a tertiary care hospital. Indian J Psychol Med 2012;34(1):30-33

58 Poongothai S, Pradeepa R, Ganesan A, Mohan V. Prevalence of depression in a large urban South Indian population-the Chennai Urban Rural Epidemiology Study (CURES-70) PLoS One 2009;4(9):e7185

59 Siddiqui S. Depression in type 2 diabetes mellitus-a brief review. Diabetes Metab Syndr 2014;8(1):62-65

60 Safita N, Islam SM, Chow CK, et al. The impact of type 2 diabetes on health related quality of life in Bangladesh: results from a matched study comparing treated cases with non-diabetic controls. Health Qual Life Outcomes 2016;14(1):129

61 Prince M, Patel V, Saxena S, et al. No health without mental health. Lancet 2007;370(9590):859-877

62 Folstein MF, Folstein SE, McHugh PR. "Mini-mental state". A practical method for grading the cognitive state of patients for the clinician. J Psychiatr Res 1975;12(3):189-198

63 Ganguli M, Ratcliff G, Chandra V, et al. A Hindi version of the MMSE: the development of a cognitive screening instrument for a largely illiterate rural elderly population in India. Int J Geriatr Psychiatry 1995; 10:367-377

64 Tsolaki M, lakovidou V, Navrozidou H, Aminta M, Pantazi T, Kazis A. Hindi Mental State Examination (HMSE) as a screening test for illiterate demented patients. Int J Geriatr Psychiatry 2000;15(7):662-664

65 Kroenke K, Spitzer RL, Williams JB. The PHQ-9: validity of a brief depression severity measure. J Gen Intern Med 2001;16(9):606-613

66 Spitzer RL, Kroenke K, Williams JB, Löwe B. A brief measure for assessing generalized anxiety disorder: the GAD-7. Arch Intern Med 2006;166(10):1092-1097
67 Grover S, Mehra A, Chakrabarti S, Avasthi A. Dropout rates and reasons for dropout from treatment among elderly patients with depression. J Geriatr Ment Health 2018;5:121-127

68 Sharma D, Mazta SR, Parashar A. Prevalence of cognitive impairment and related factors among elderly: a population-based study. J Dr NTR Univ Health Sci 2013;2:171-176

69 Sengupta P, Benjamin AI, Singh Y, Grover A. Prevalence and correlates of cognitive impairment in a north Indian elderly population. WHO South-East Asia J Public Health 2014;3(2):135-143

70 Shaji S, Bose S, Verghese A. Prevalence of dementia in an urban population in Kerala, India. Br J Psychiatry 2005;186:136-140

71 Poddar K, Kant S, Singh A, Singh TB. An epidemiological study of dementia among the habitants of eastern Uttar Pradesh, India. Ann Indian Acad Neurol 2011;14(3):164-168

72 Raina S, Razdan S, Pandita KK, Raina S. Prevalence of dementia among Kashmiri migrants. Ann Indian Acad Neurol 2008;11(2):106-108

73 Ren L, Bai L, Wu Y, et al. Prevalence of and risk factors for cognitive impairment among elderly without cardio- and cerebrovascular diseases: a population-based study in Rural China. Front Aging Neurosci 2018;10:62

74 Gao Y, Xiao Y, Miao R, et al. The prevalence of mild cognitive impairment with type 2 diabetes mellitus among elderly people in China: a cross-sectional study. Arch Gerontol Geriatr 2016;62:138-142

75 Ji Y, Shi Z, Zhang Y, et al. Prevalence of dementia and main subtypes in rural northern China. Dement Geriatr Cogn Disord 2015;39(5-6):294-302

76 Langa KM, Larson EB, Crimmins EM, et al. A comparison of the prevalence of dementia in the United States in 2000 and 2012. JAMA Intern Med 2017;177(1):51-58

77 Lavielle P, Talavera JO, Reynoso N, et al; DIMSS Study Group. Prevalence of cognitive impairment in recently diagnosed type 2 diabetes patients: are chronic inflammatory diseases responsible for cognitive decline? PLoS One 2015;10(10):e0141325

78 Dos Santos Matioli MNP, Suemoto CK, Rodriguez RD, et al. Diabetes is not associated with Alzheimer's disease neuropathology. J Alzheimers Dis 2017;60(3):1035-1043

79 Pandav R, Dodge HH, DeKosky ST, Ganguli M. Blood pressure and cognitive impairment in India and the United States: a cross-national epidemiological study. Arch Neurol 2003;60(8):1123-1128

80 Posner HB, Tang MX, Luchsinger J, Lantigua R, Stern Y, Mayeux R. The relationship of hypertension in the elderly to $\mathrm{AD}$, vascular dementia, and cognitive function. Neurology 2002;58(8):1175-1181

81 Elias PK, Elias MF, D'Agostino RB, et al. NIDDM and blood pressure as risk factors for poor cognitive performance. The Framingham Study. Diabetes Care 1997;20(9):1388-1395

82 Verma M, Grover S, Tripathy JP, et al. Co-existing non-communicable diseases and mental illnesses amongst the elderly in Punjab, India. Eur Endocrinol 2019;15(2):106-112 